\title{
Effect of Temperature Change on Geometric Structure of Isolated Mixing Regions in Stirred Vessel
}

\author{
Nor Hanizah Shahirudin, Alatengtuya, Norihisa Kumagai, \\ Takafumi Horie, and Naoto Ohmura \\ Department of Chemical Science and Engineering, Kobe University, 1-1 Rokkodai, Nada, Hyogo, Kobe 657-8501, Japan \\ Correspondence should be addressed to Naoto Ohmura, ohmura@kobe-u.ac.jp
}

Received 11 February 2012; Accepted 5 April 2012

Academic Editor: See-Jo Kim

Copyright ( 2012 Nor Hanizah Shahirudin et al. This is an open access article distributed under the Creative Commons Attribution License, which permits unrestricted use, distribution, and reproduction in any medium, provided the original work is properly cited.

\begin{abstract}
The present work experimentally investigated the effect of temperature change on the geometric structure of isolated mixing regions (IMRs) in a stirred vessel by the decolorization of fluorescent green dye by acid-base neutralization. A four-bladed Rushton turbine was installed in an unbaffled stirred vessel filled with glycerin as a working fluid. The temperature of working fluid was changed in a stepwise manner from $30^{\circ} \mathrm{C}$ to a certain fixed value by changing the temperature of the water jacket that the vessel was equipped with. The step temperature change can dramatically reduce the elimination time of IMRs, as compared with a steady temperature operation. During the transient process from an initial state to disappearance of IMR, the IMR showed interesting three-dimensional geometrical changes, that are, simple torus with single filament, simple torus without filaments, a combination of crescent shape and circular tori, and doubly entangled torus.
\end{abstract}

\section{Introduction}

Stirred vessels are frequently used to homogenize different substances, conduct chemical reactions, and enhance mass transfer between different phases. These vessels are versatile and they are available in a wide variety of sizes and impeller configurations for use in industrial processes. Although turbulent flow is efficient for mixing, laminar mixing is required in some cases such as for high-viscosity fluids and shearsensitive materials. Koiranen et al. [1] proposed specific principles for effective mixing of highly viscous liquids or shear-sensitive materials in laminar flow mixing regimes. In these regimes, global mixing is inefficient due to the existence of isolated mixing regions (IMRs). Makino et al. [2] characterized IMRs in a stirred vessel using radial flow impellers and found that IMRs consisted of various KolmogorovArnold-Moser (KAM) tori. Ohmura et al. [3] reported the existence of KAM tori as island structures in a phase-locked orbit that has a rational relation of the time period between the primary and secondary circulation flows. Noui-Mehidi et al. [4] found that the mechanism of IMR disappearance could be described by the formation of a period-doubling locus in the physical space when using a six-blade Rushton turbine impeller. Hashimoto et al. [5] successfully visualized a three-dimensional structure of thin filaments spirally wrapping around the core of toroidal region. They formulated and estimated the relation between mixing conditions and filament numbers and/or wire turns.

The elimination of IMR at low Reynolds numbers has also been studied extensively. Lamberto et al. [6] and Yao et al. [7] demonstrated that IMRs could be eliminated by using an unsteady rotation method. Takahashi and Motoda [8] proposed a method in which relatively large objects are introduced to the system in order to improve the mixing performance. Nishioka et al. [9] also found that small particles released at the liquid surface were captured within IMRs. Alatengtuya et al. [10] showed that the motion of small particles improves the material transfer between IMRs and the surrounding active mixing region (AMR).

Although research studies on IMRs in stirred vessels have been conducted extensively, few have paid attention to the effect of temperature change on laminar mixing. As industrial batch processes using stirred vessels are often conducted under nonisothermal conditions, it is crucial to 


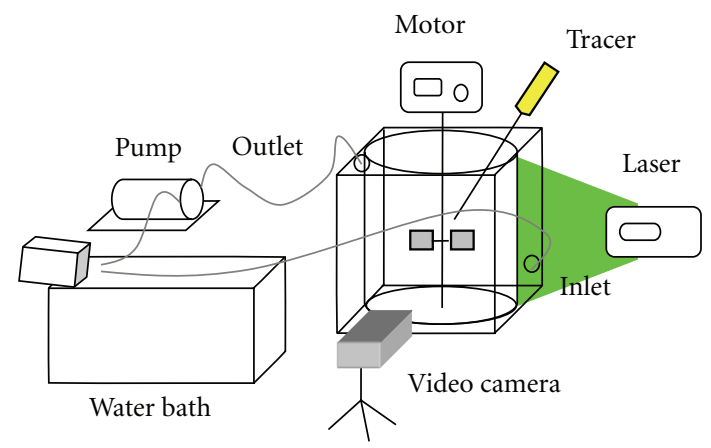

FIgURE 1: Experimental apparatus for flow visualization.

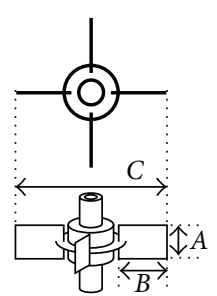

Four-bladed Rushton impeller

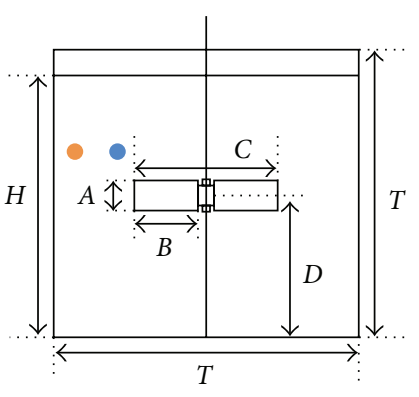

Thermocouple position

- IMR

- AMR
$A=0.02 \mathrm{~m}$

$B=0.035 \mathrm{~m}$

$C=0.1 \mathrm{~m}$

$D=0.1 \mathrm{~m}$

$T=0.2 \mathrm{~m}$

$H=0.18 \mathrm{~m}$

FIgURE 2: Configuration and location of a four bladed turbine impeller and position of thermocouples.

obtain knowledge of the effect of thermal unsteadiness on laminar mixing. This study, therefore, investigated transient behaviors of isolated mixing regions undergoing change of temperature in a stirred vessel.

\section{Experimental}

The mixing system consisted of a cylindrical flat-bottom vessel with the diameter of $0.1 \mathrm{~m}$ without a baffle and a four-bladed Rushton turbine, as shown in Figure 1. The cylindrical vessel was immersed in a square vessel of acrylic resin filled with water so that the temperature of glycerin solution was controlled by feeding water from a water bath, and photographic distortion was reduced. The dimensions and location of the impeller are shown in Figure 2. The impeller was installed $0.1 \mathrm{~m}$ from the bottom of the vessel. Hence, the ratio of impeller off-bottom clearance to the tank diameter, $D / T$, was 0.5 .

The working fluid was glycerine $\left(\rho=1260 \mathrm{~kg} / \mathrm{m}^{3}\right.$, where $\mu=0.53 \mathrm{~Pa} \mathrm{~s}$ at $\left.30^{\circ} \mathrm{C}\right)$. A fluorescent, $\mathrm{pH}$ sensitive and neutrally buoyant green dye, uranine, was used as a passive tracer to observe the mixing process. A small amount of basic solution made of $5 \mathrm{~mL} 1 \mathrm{~N} \mathrm{NaOH}$ and $20 \mathrm{~mL}$ glycerin was added to the working fluid. After the impeller reached $67 \mathrm{rpm}$ of rotational speed and glycerin temperature reached $30^{\circ} \mathrm{C}$ (the initial Reynolds number can be estimated at $R e=27$ ), a small amount of acidic solution made of $5 \mathrm{~mL} 1 \mathrm{~N} \mathrm{HCl}$ and
$20 \mathrm{~mL}$ glycerin was injected approximately $1 \mathrm{~cm}$ away from the shaft and near to the center of impeller to decolorize the green dye by neutralization reaction. Then the feed of water was stopped for 30 minutes to maintain a stable IMR structure. While the glycerin temperature was kept at $30^{\circ} \mathrm{C}$, the water bath temperature was changed to a fixed higher temperature $\left(40,50,60^{\circ} \mathrm{C}\right)$. Then, the water was fed into the jacket after 30 minutes. The cross-sectional view of IMRs was visualized using a plane sheet of semiconductor laser light. The images of decolorization process were recorded by a digital video camera.

To measure the temperature in the upper IMR and its surrounding AMR, an experiment independent of the above flow visualization was conducted using two thermocouples. The positions of the two thermocouples were determined by the flow visualization experiment as shown in Figure 2 where the dots represent the thermocouples. One thermocouple was set in the upper IMR, and the other one was set in AMR.

\section{Results and Discussion}

3.1. Transition of IMR Structure. Figures 3 and 4 show overviews and cross-sectional views of IMR transition, respectively. One similarity in all of the experiments is that the upper torus is eliminated before the lower torus. Influence of the free liquid surface at the top of the stirred tank makes the volume of the upper torus structure smaller 


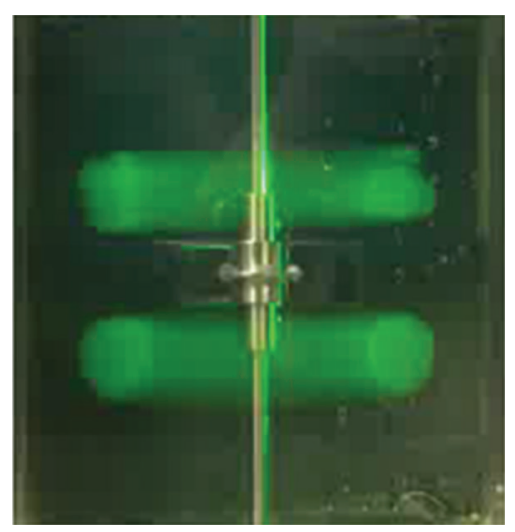

(a)

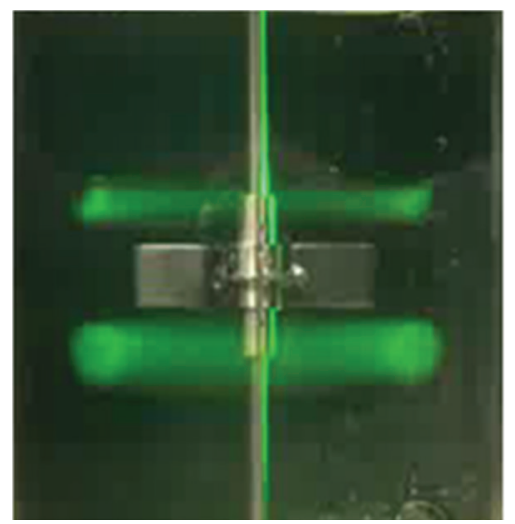

(d)

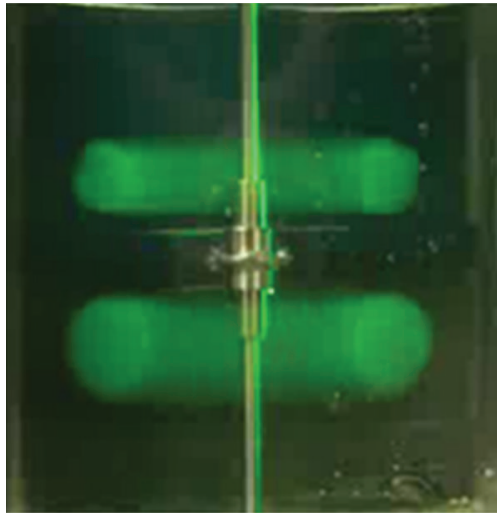

(b)

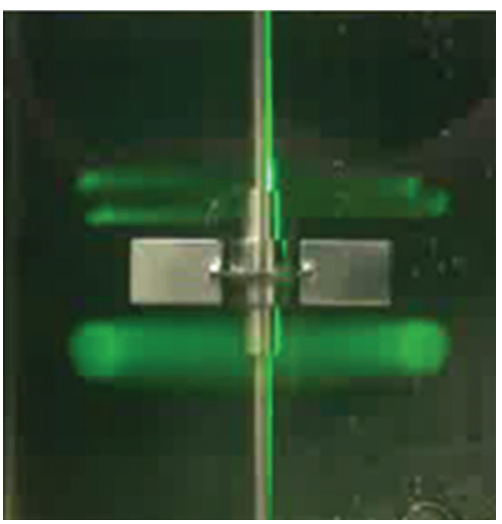

(e)

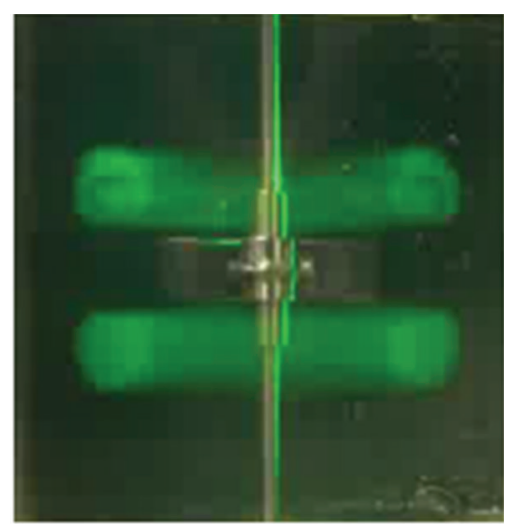

(c)

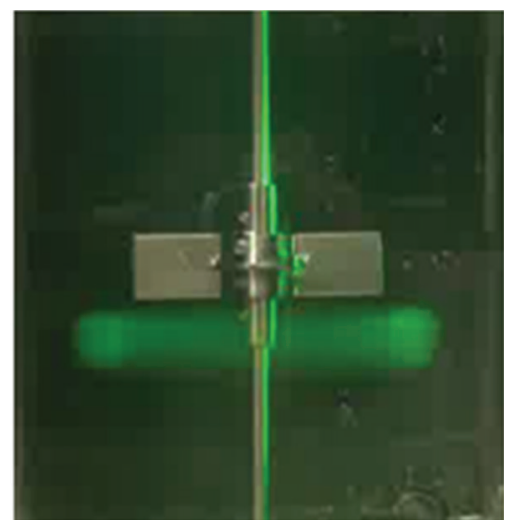

(f)

FIgURe 3: Overviews of IMR transition, $\Delta T=10 \mathrm{~K}$.

than volume of the lower torus structure resulting in the elimination of the upper IMR first and later the lower IMR. Moreover, a larger temperature difference enhances the diffusion mechanism between IMR and AMR more easily. As illustrated in Figures 3(a) and 4(a), when the glycerin solution is maintained at $30^{\circ} \mathrm{C}$, IMR is created above and below the impeller while it is preserved for 30 minutes to obtain a stable IMR structure. Since more acid is used compared to base, mixed regions of the stirred tank contain excess acid, causing the indicator in these regions to appear colorless. Segregated regions, on the other hand, contain unreacted base and display a green color. Lamberto et al. [6] explain that these regions remain segregated from the rest of the system and are not mixed by convective flow mechanisms. As time increases, single filament wrapped around the upper torus where the filament whose crosssection appears as islands formed small tori.

As temperature increases, the filament simultaneously disappear by diffusion and leave only the core torus as shown in Figures 3(b) and 4(b). After a few minutes, a large amount of fluid from the AMR penetrates into the coherent structure of IMRs resulting in combination of torus and crescent shape from the cross-section view. These shapes remain stable while the fluids inside both shapes rotate counterclockwise. Influence from the temperature difference between AMR and IMR enhances the erosion at the "outer" shells of the toroidal regions, corresponding to Figures 3(c) and 4(c). This phenomenon continues for several minutes and returns to a stable toroidal shape. This toroidal shape becomes narrow, forming an ellipse as in Figures $3(\mathrm{~d})$ and $4(\mathrm{~d})$. Later, it continues to form a spiral structure of string IMR [11] that appeared as two islands from the cross-sectional view as in Figures 3(e) and 4(e). These islands' cross-sectional area decreases slowly and finally the string IMR gradually disappears, as shown in Figures 3(f) and 4(f). The abovementioned results indicate that changing the temperature by steps can dramatically reduce the elimination time of IMRs, as compared with a steady temperature operation. This mixing enhancement might be attributed to dynamic change of flow structure due to decrease of viscosity when temperature increases. The changes of IMR structures occurred in both upper and lower IMR for different temperature variations.

\subsection{Time Variations of Temperature of IMR and AMR.} Figure 5 shows the time variation of temperature of IMR and AMR. Points notated from (c) to (f) in Figure 5 correspond to Figures 3 and 4 . As can be seen from the graph, there is slight temperature difference between IMR and AMR for all of the temperature variations. With only $1^{\circ} \mathrm{C}$ to $2^{\circ} \mathrm{C}$ of temperature increase from the initial temperature, the changes of IMR structure started to occur. The curve in every graph for the upper IMR temperature is identical, where there is 


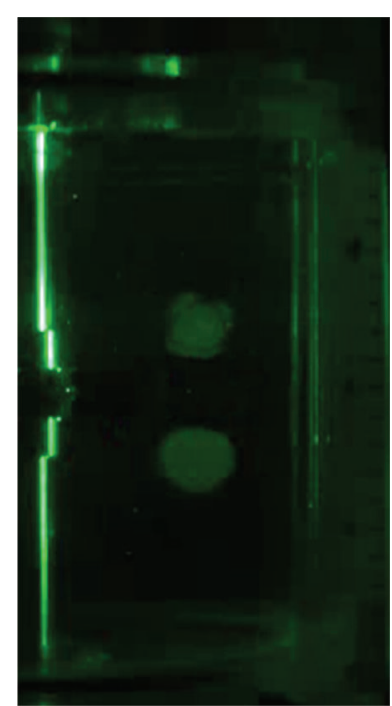

(a)

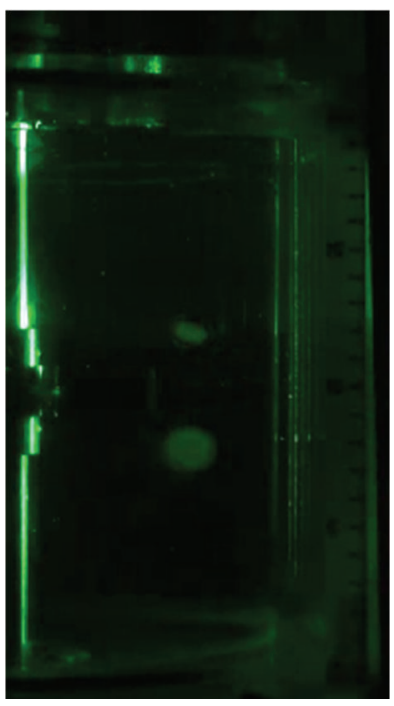

(d)

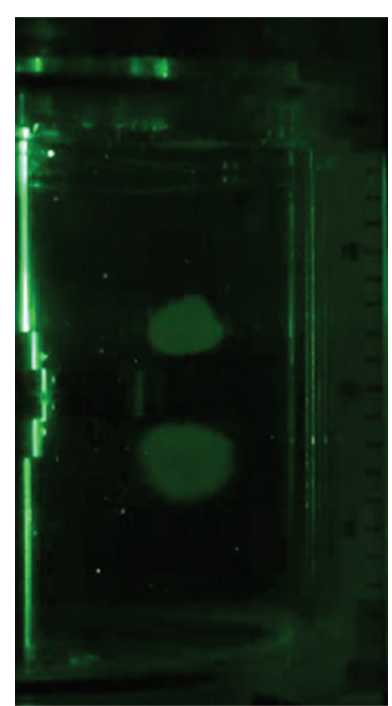

(b)

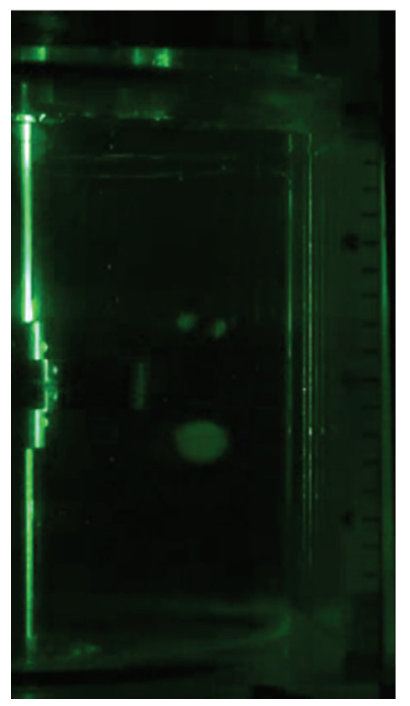

(e)

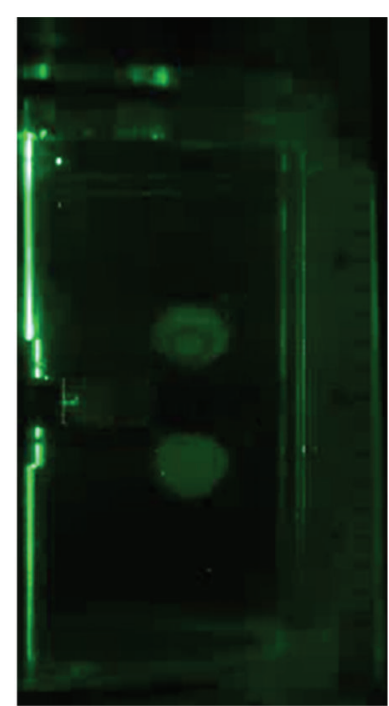

(c)

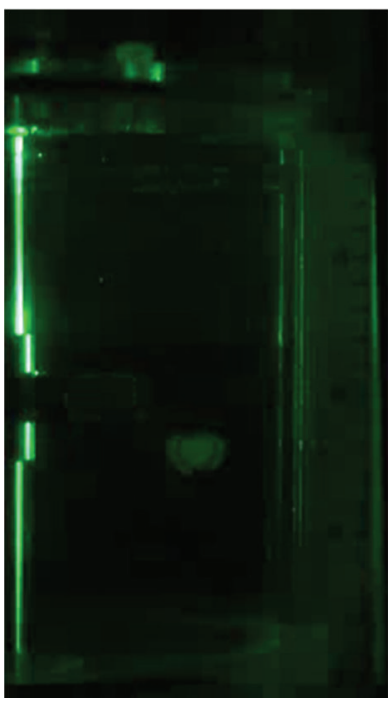

(f)

FIGURE 4: Cross-sectional views of IMR transition, $\Delta T=10 \mathrm{~K}$.

a curve-step-like change. There is a unique characteristic indicated at (c) where the time is equivalent to the time during formation of torus and crescent shape. At point (d), as temperature increased continuously the formation of a narrow torus occurred and later a spiral structure of string IMR formed, at (e). During the elimination of the segregated region, there is no temperature difference between the two positions, as indicated at (f). Although the points in Figure 5 do not perfectly match the flow structures shown in Figures 3 and 4 because of the disturbance caused by a thermocouple in the IMR structure, nonetheless it can be seen that influence from the nonuniformity of temperature in the stirred tank allowed more interaction between IMR structure and AMR.
3.3. Dimensionless Time for Every Step of IMR Structure Transformation. Figure 6 displays the relation between dimensionless time against initial temperature difference for the upper and lower IMRs. The dimensionless time is defined as $t^{*}=t / t_{e}$, where $t_{e}$ is the elimination time of IMRs, which is one criterion for mixing time. The $t^{*}$ value when the combination of torus and crescent shape is formed can be considered constant while the $t^{*}$ value during the formation of narrow torus and string IMR is proportional to the initial temperature difference. The dimensionless time in each step of IMR changes for $10 \mathrm{~K}$ temperature difference is the smallest compared to other temperature differences. The temperature step changes for $10 \mathrm{~K}$ temperature difference increase very slowly, which decreases the diffusive 

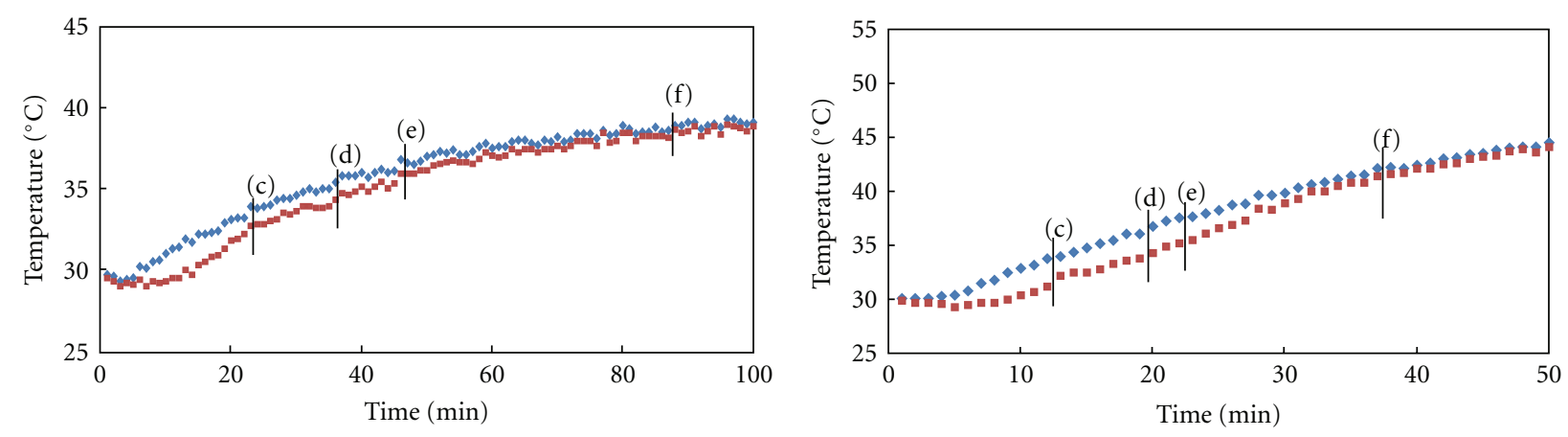

- AMR

- AMR

- IMR

- IMR

(a)

(b)

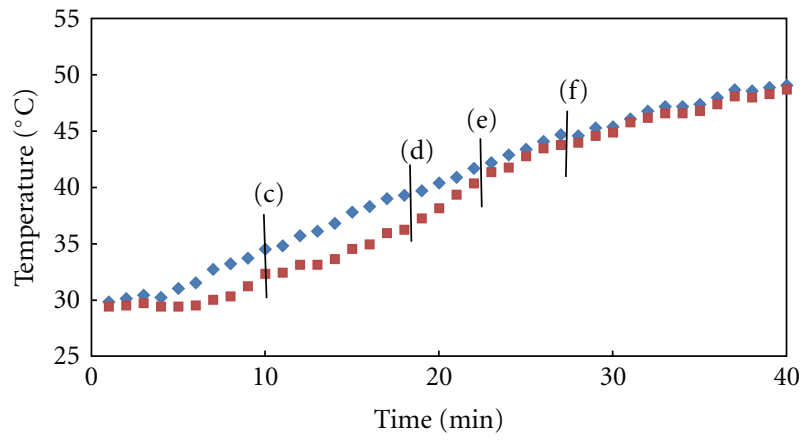

- AMR

- IMR

(c)

FIGURE 5: Time variation of temperature in the upper IMR and AMR: (a) $\Delta T=10 \mathrm{~K}$, (b) $\Delta T=20 \mathrm{~K}$, and (c) $\Delta T=30 \mathrm{~K}$.

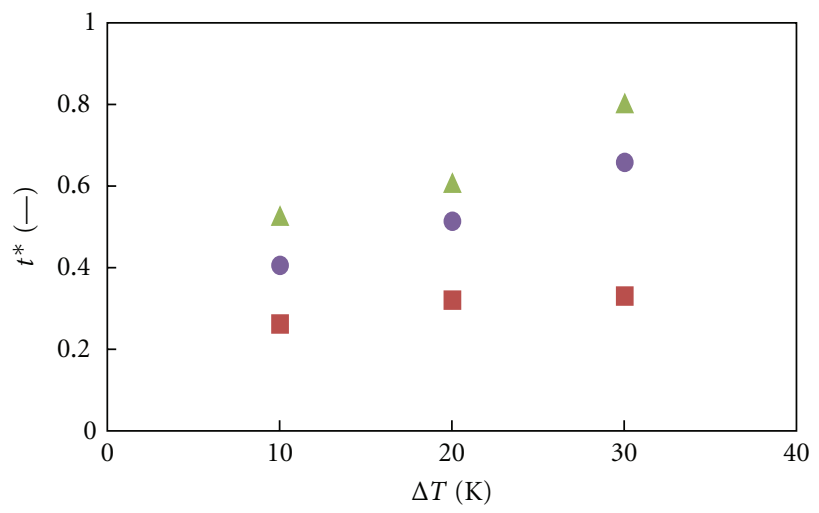

- (c) Combination of torus and crescent shape - (d) Narrow torus

$\Delta$ (e) String IMR

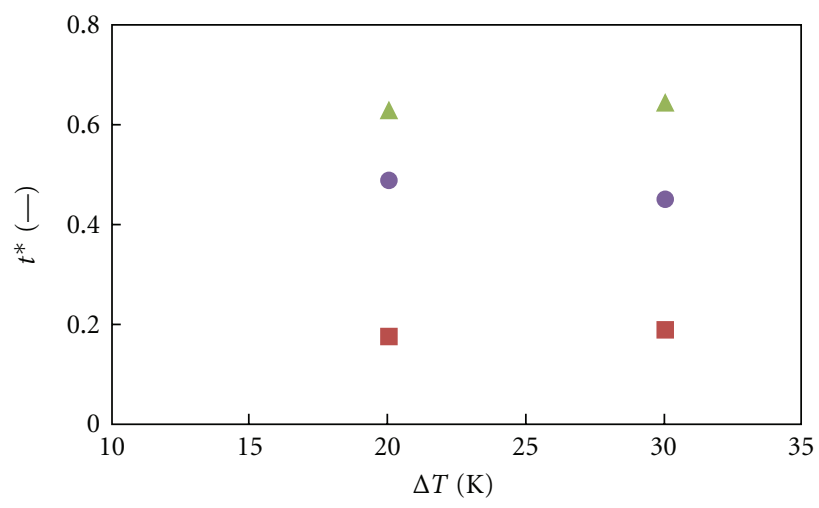

(c) Combination of torus and crescent shape - (d) Narrow torus

$\Delta$ (e) String IMR

FIGURE 6: Dimensionless time as geometric structures of IMRs against temperature difference: (a) the upper IMR and (b) lower IMR. 
mechanism between IMR and AMR. Therefore, the time for each process of IMR transformation needs to be lengthened. Moreover, it can also be considered that influence from the free surface liquid causes different trends in the results of upper IMR. Compared to the dimensionless time for upper IMR, dimensionless time for lower IMR is nearly constant for all steps of IMR structure changes. This is because the flow circulation in the lower region becomes weaker due to the existence of the bottom.

\section{Conclusion}

Presence of IMRs in a stirred vessel interrupts the process of achieving uniform mixing. Temperature changes from the jacket vessel can impact the structure of IMR. In this research, as the temperature started to change, the IMR structure transformed from a combination of crescent shape and torus, to narrow torus, to a spiral structure of string IMR, and finally the IMR disappeared. Influence from the step temperature change of the outer jacket enhances the elimination of IMR. Moreover, as the temperature difference increases, the time to eliminate IMR decreases by enhancing global mixing in the stirred vessel because a larger temperature difference enhances diffusion mechanism between IMR and AMR more easily.

\section{Nomenclature}

\author{
A: Height of turbine blade [m] \\ $B$ : Length of turbine blade [m] \\ $C$ : Impeller diameter $[\mathrm{m}]$ \\ $D$ : Impeller off-bottom clearance [m] \\ $H$ : Liquid height $[\mathrm{m}]$ \\ $T$ : Diameter and height of vessel $[\mathrm{m}]$ \\ T: Temperature [K] \\ $t$ : Time [min] \\ $t_{e}$ : Elimination time of IMRs [min] \\ $t^{*}$ : Dimensionless time $\left(=t / t_{e}\right)[-]$.
}

\section{Greek Letters}

$$
\begin{aligned}
& \mu: \text { Viscosity }[\mathrm{Pa} \cdot \mathrm{s}] \\
& \rho: \text { Density }\left[\mathrm{kg} \cdot \mathrm{m}^{-3}\right] .
\end{aligned}
$$

\section{Acknowledgments}

This research was supported by the Ministry of Education, Science, Sports, and Culture of Japan, Grant-in-Aid for Scientific Research (A) (no. 20246115) and Grant-in-Aid for Challenging Exploratory Research (no. 23656492) from the Japan Society for the Promotion of Science (JSPS).

\section{References}

[1] T. Koiranen, A. Kraslawski, and L. Nyström, "Knowledgebased system for the preliminary design of mixing equipment," Industrial and Engineering Chemistry Research, vol. 34, no. 9, pp. 3059-3067, 1995.
[2] T. Makino, N. Ohmura, and K. Kataoka, "Observation of isolated mixing regions in a stirred vessel," Journal of Chemical Engineering of Japan, vol. 34, no. 5, pp. 574-578, 2001.

[3] N. Ohmura, T. Makino, T. Kaise, and K. Kataoka, "Transition of organized flow structure in a stirred vessel at low Reynolds numbers," Journal of Chemical Engineering of Japan, vol. 36, no. 12, pp. 1458-1463, 2003.

[4] M. N. Noui-Mehidi, N. Ohmura, J. Wu, B. Van Nguyen, N. Nishioka, and T. Takigawa, "Characterisation of isolated mixing regions in a stirred vessel," International Journal of Chemical Reactor Engineering, vol. 6, article no. A25, 2008.

[5] S. Hashimoto, H. Ito, and Y. Inoue, "Experimental study on geometric structure of isolated mixing region in impeller agitated vessel," Chemical Engineering Science, vol. 64, no. 24, pp. 5173-5181, 2009.

[6] D. J. Lamberto, F. J. Muzzio, P. D. Swanson, and A. L. Tonkovich, "Using time-dependent RPM to enhance mixing in stirred vessels," Chemical Engineering Science, vol. 51, no. 5, pp. 733-741, 1996.

[7] W. G. Yao, H. Sato, K. Takahashi, and K. Koyama, "Mixing performance experiments in impeller stirred tanks subjected to unsteady rotational speeds," Chemical Engineering Science, vol. 53, no. 17, pp. 3031-3040, 1998.

[8] K. Takahashi and M. Motoda, "Chaotic mixing created by object inserted in a vessel agitated by an impeller," Chemical Engineering Research and Design, vol. 87, no. 4, pp. 386-390, 2009.

[9] N. Nishioka, Y. Tago, T. Takigawa, N. M. Noui-Mehidi, J. $\mathrm{Wu}$, and N. Ohmura, "Particle migration in a stirred vessel at low reynolds numbers," in Proceedings of the 8th Italian Conference on Chemical and Process Engineering (AIDIC Conference Series), vol. 8, pp. 243-247, Milano, Italy, 2007.

[10] Alatengtuya, N. Nishioka, T. Horie, M. N. Noui-Mehidi, and N. Ohmura, "Effect of particle motion in isolated mixing regions on mixing in stirred vessel," Journal of Chemical Engineering of Japan, vol. 42, no. 7, pp. 459-463, 2009.

[11] Y. Inoue, H. Ito, Y. Nakata, and S. Hashimoto, "Theoretical analysis of isolated mixing regions in stirred vessels," Kagaku Kogaku Ronbunshu, vol. 36, no. 1, pp. 1-16, 2010. 

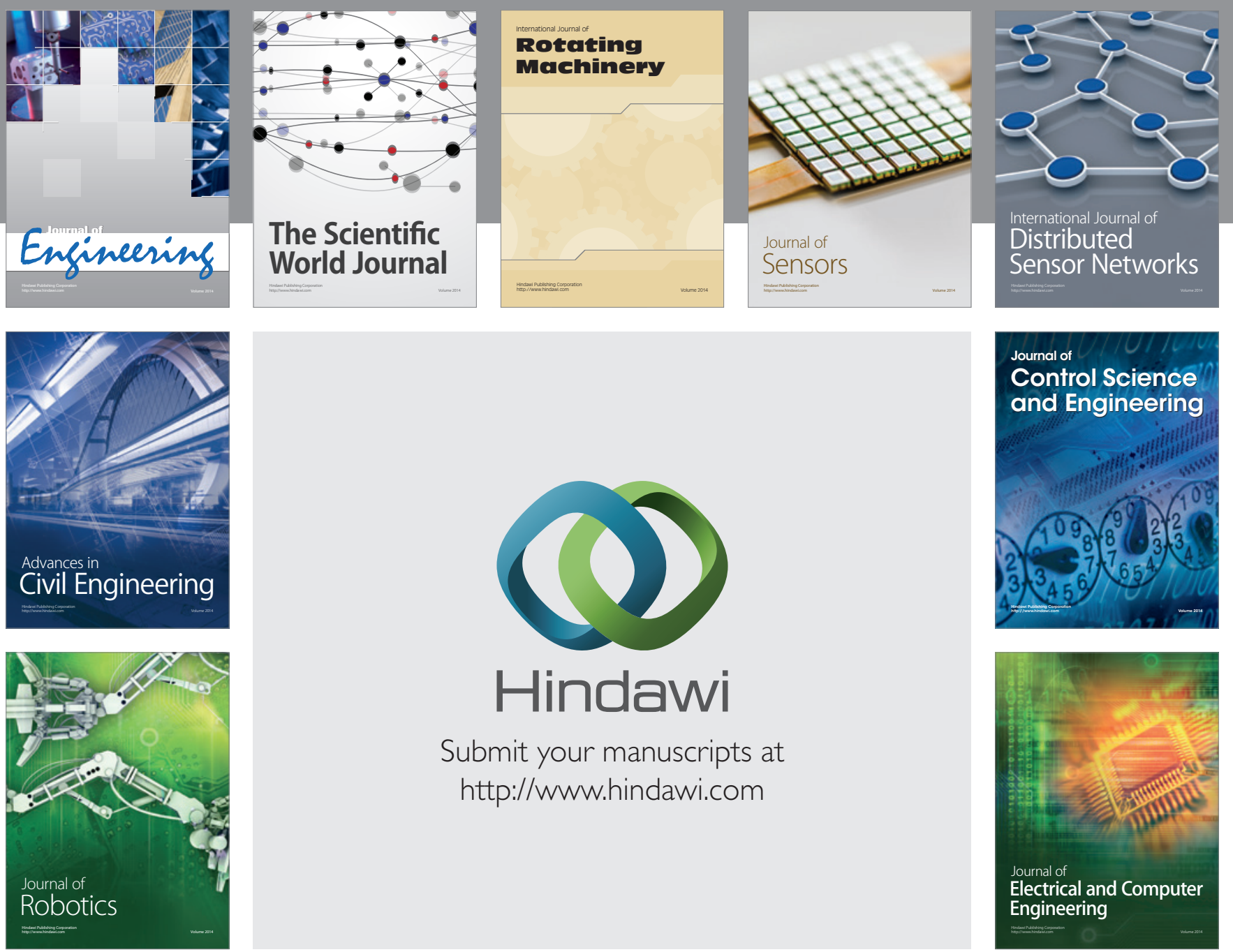

Submit your manuscripts at

http://www.hindawi.com
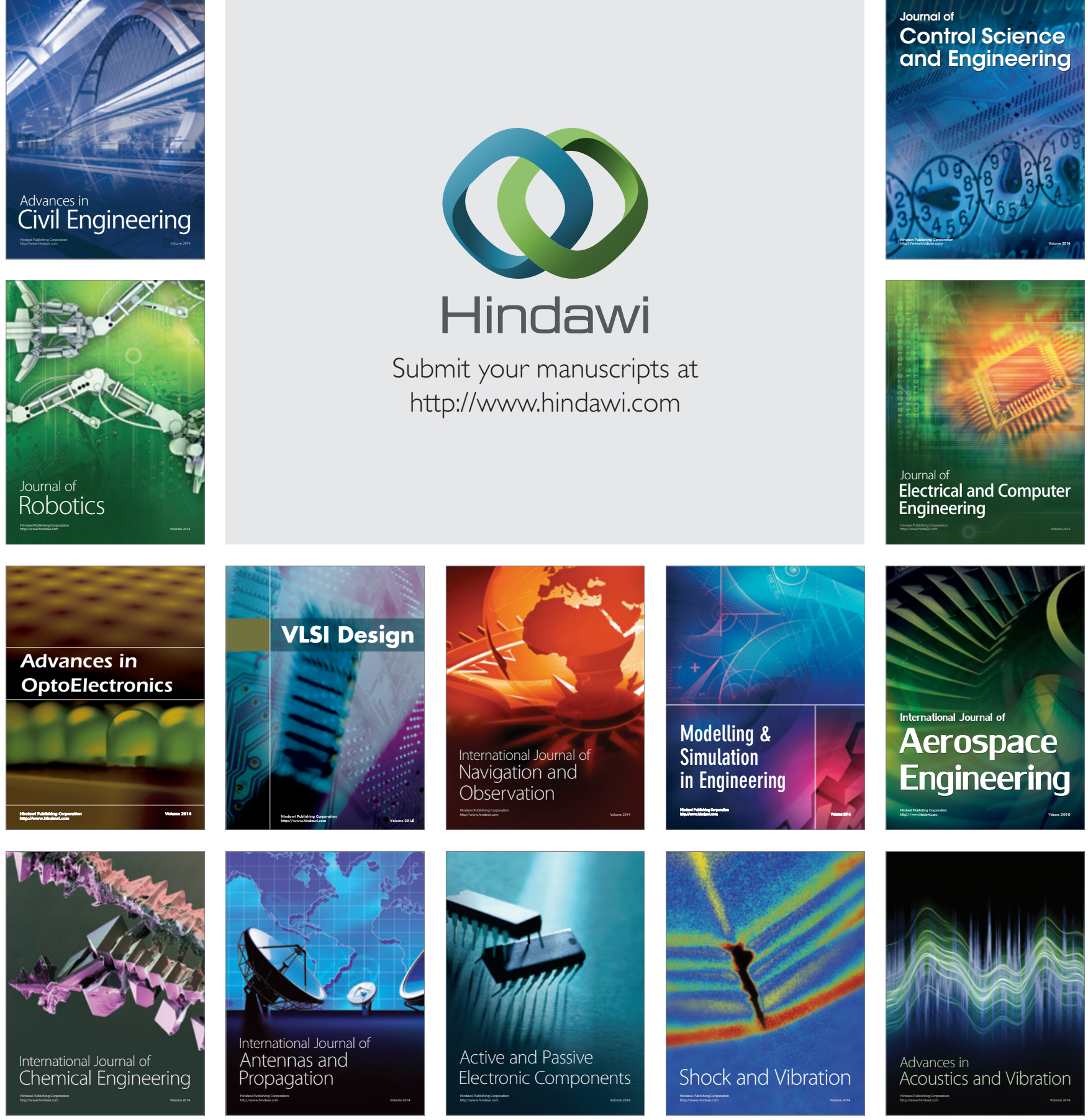